\title{
TÁTICAS EDITORIAIS EM TEMPO DE PUBLICAÇÃO CONTÍNUA: IDENTIDADE E CRIATIVIDADE
}

\author{
Maria Cristina Menezes \\ CIVILIS/FE/UNICAMP \\ Maria de Lourdes Pinheiro \\ CIVILIS/FE/UNICAMP \\ Joel Martins Luz \\ Universidade Federal do Mato Grosso
}

\section{RESUMO}

Em Editorial da Edição 2019 da RIDPHE_R, Revista Iberoamericana do Patrimônio Histórico Educativo, em publicação contínua a partir do ano supracitado, destaca-se o fato de a Revista trazer a $2^{\mathbf{a}}$ parte do dossiê "Patrimônio-Educativo e História Oral: Subjetividades e Diversidades na Contemporaneidade", cuja $1^{a}$ parte foi publicada no v. 4. n.2 de 2018, com capa temática a ele voltada. Na edição 2019, publicou-se na íntegra o dossiê "Materiais para o ensino de matemática nos primeiros anos escolares: condensando saberes pedagógicos e disciplinares" e a capa da edição 2019 apresenta tema que a ele se articula. Outro destaque, a recepção de artigos e documento com enfoques culturais diversos, ao se considerar a dimensão educacional das práticas patrimoniais culturais.

Palavras-chave: Patrimônio histórico-educativo e cultural. História oral, Cultura material.

\section{INTRODUÇÃO}

Chegamos à publicação da oitava edição da RIDPHE_R, Revista Iberoamericana do Patrimônio Histórico-Educativo, a despeito de se ler "v. 4, n. 2, (2018)" na última edição publicada; e, na apresentação do dossiê, ter sido anunciado que a segunda parte do dossiê "Diversidades e subjetividades nas relações entre patrimônio Educativo e História Oral da contemporaneidade", seria publicado no número seguinte da Revista, que seria v.5, n. 1, esta nova edição se apresenta como o quinto volume da RIDPHE_R; em Publicação Contínua, anual. A nova numeração desta edição, que agora se publica, traz adesão à numeração padronizada que se busca às Revistas.

Nas sete edições anteriores, foi sempre uma aventura, a despeito do árduo e laborioso trabalho a que são solicitadas(os) os (as) editoras (es). Movimentação contínua nos meses 


\section{$(\mathrm{cc}) \overline{E Y}$}

anteriores às edições e, ao final de cada uma, uma nova capa, um novo editorial, organização das seções, apresentação dos dossiês, em trabalho intermitente.

A primeira publicação da RIDPHE_R veio a lume em final de 2015, com o v. $1 \mathrm{n}$. 1 houve a inauguração da Revista. Em 2016 foram publicados os v. 2 n. 1 e vol. 2 n.2, com essa sequência nos anos continuados.

A edição final de 2019 foi vivenciada em um novo tempo da Revista, um reaprender a editoração, no decurso do ano os textos foram sendo inseridos. Entretanto, o primeiro lote de escritos das diversas seções da Revista foi divulgado tal como já haviam sido publicadas as edições anteriores, editorial incluso. Estávamos, os editores, aprendendo.

O trabalho árduo de ler e agrupar artigos diversos; remeter aos pareceristas; acompanhar idas e vindas; inventariar e articular os textos visando a apresentação de temático ou coligir artigos com temas e procedências diversas; organizar seções; ao se buscar fechar uma edição e vê-la pronta. Outrossim, pensar a capa, em interlocução à edição, ao temático, como se deu de forma reiterada desde a edição inaugural da revista, o que se constitui pelos múltiplos olhares, elaboração conjunta, entre editores, proponentes de dossiês e demais seções.

Ao se adequar a revista à edição anual algo doloroso aflorou, a princípio. Entretanto, se pondera ao que se visa, como compartilhar espaço e diálogo com outras revistas de cunho científico, em linguagem, procedimentos e agilidade anunciada. São aspectos técnicos que buscam precisão maior em relação à captação de dados, à publicação dos artigos. Por outro lado, a personalidade das diferentes publicações não pode deixar de existir, e a criatividade deve persistir.

Se o momento anterior estava em engendrar esforços com foco em publicação quadrimestral, eis que mudam os ventos com a rapidez do ritmo digital.

O mais adequado estava em envidar esforços na publicação contínua, assim a criação de uma capa, "template", enunciativa da publicação contínua anual, trouxe momento especial de criação e elaboração de capa, que ao ser visualizada quando do acesso à revista, deveria conter projeto gráfico articulado ao escopo da revista.

Nova experiência, uma publicação contínua em que os artigos podem ser inseridos em blocos e em vários momentos da publicação anual, todavia, com regularidade. Somente ao final do ano, ao se fechar a publicação anual, se publica um sumario completo e também se projeta uma capa da edição. Os autores, por sua vez, buscam maior rapidez na visualização dos respectivos artigos na publicação.

Rev. Iberoam. Patrim. Histórico-Educativo, Campinas (SP), v. 5, p. 1-8, e019001, 2019. 
Destarte, no compasso de publicação contínua e laborioso trabalho coletivo, anunciamos a primeira publicação anual da RIDPHE_R. As seções permanecem tal como nas publicações anteriores.

DOSSIÊ 1 - lançado em 2018 - ( $2^{\mathrm{a}}$ parte em 2019)

Na seção Dossiê, a Revista publicou em $20192^{a}$ parte do Dossiê Intitulado "PatrimônioEducativo e História Oral: Subjetividades e Diversidades na Contemporaneidade", de 2018, n. 2, período no qual a capa da edição 2018 foi apropriada à temática do Dossiê, organizado pelas Professoras Andrea Paula dos Santos Oliveira Kamensky, UFABC, Maria Lucia Mendes de Carvalho, GEPEMHEP/CPS, e Suzana Lopes Salgado Ribeiro, UNITAU/UNIS.

O Dossiê sobre Patrimônio-Educativo e História Oral, $1^{\text {a }}$ parte, cujo lançamento ocorreu em 2018, teve a segunda parte publicada no primeiro lote de artigos da Edição Contínua de 2019 da RIDPHE_R.

A $2^{\mathrm{a}}$ parte deste dossiê, que veio a lume no primeiro lote de artigos lançado em 2019, reuniu textos de diferentes estados do Brasil e um artigo sobre as fotografias da Escola Normal do Estado de San Luis Potosí, no México, apresentando a tradição das Escolas Normais no país, como a de San Luís Potosí, com 169 anos.

A diversidade temática do dossiê também impressiona, uma vez que agrega textos, além do supracitado das fotografias escolares; como narrativas sobre a formação de professores; ensino técnico de música; a questão da velhice no âmbito do patrimônio rural paulista, projeto de educação no campo; dois artigos tratam de pessoas com deficiência visual, um deles traz sobre o ingresso na educação básica e outro sobre o percurso acadêmico de pessoas com deficiência visual; organização de centro de memória; história do movimento estudantil; dispensário de puericultura de uma Escola Profissional Feminina.

A $2^{\mathbf{a}}$ parte deste dossiê, lançado no $1^{\mathbf{0}}$ lote de artigos de 2019, e com capa em 2018, enriqueceu a revista com temas pertinentes que acenam para um campo já consolidado, o da história oral. 
$(\infty c)$ EY

DOSSIÊ 2 - lançado em 2019

\section{CAPA EDIÇÃO 2019}

A CAPA da RIDPHE_R Edição Contínua 2019, se articula ao Dossiê Temático "Materiais para o ensino de matemática nos primeiros anos escolares: condensando saberes pedagógicos e disciplinares", lançado pela Revista em 2019 e organizado por Wagner Rodrigues Valente, Coordenador do GHEMAT - Grupo de Pesquisa de História da Educação Matemática (www.unifesp.br/centros/ghemat).

A estampa da capa 2019, da RIDPHE_R, permite que se visualize imagem de capa do manual de ensino Arithmetica Primária, de Antonio Trajano. Trata-se da $12^{\circ}$ Edição do Manual, editado pela "Companhia Typographica do Brazil", do Rio de Janeiro, de 1895. Para maiores informes desse importante documento do século XIX, voltado ao ensino da matemática nos primeiros anos escolares, sugere-se visita ao Repositório Institucional da UFSC, de acesso aberto e gratuito, no qual o manual poderá ser acessado na íntegra no endereço: Arithmetica primária https://repositorio.ufsc.br/handle/123456789/104083

Perante a importância do GHEMAT, em nível nacional e internacional, a chamada aberta ao Dossiê, divulgada na RIDPHE_R conclamou historiadores da História da Educação Matemática de diversas procedências.

Foram publicados doze textos no Dossiê Materiais para o ensino de matemática nos primeiros anos escolares, em sua apresentação o Prof. Valente destaca que os anos finais do século XIX foram de grande expansão ao uso e à produção de novos materiais para o ensino dos primeiros passos na matemática. De modo que os textos reunidos nesse Dossiê Temático abrangem largo período "desde finais do século retrasado até a atualidade” (Valente, 2019, p.1).

Contribuíram com seus artigos seguindo a proposta do dossiê e trazendo profícua interlocução aos estudiosos desta área de conhecimento, como também aos demais leitores interessados com a preservação e difusão do patrimônio histórico escolar, pesquisadores brasileiros e mexicanos. Do Brasil participaram 2 pesquisadores e 1 pesquisadora do Paraná; 2 pesquisadores de Santa Catarina; 1 pesquisadora do Rio Grande do Sul; 3 pesquisadoras de Minas Gerais; 1 pesquisadora e 1 pesquisador do Mato Grosso do Sul; 1 pesquisador da Paraíba; 1 pesquisador do Maranhão; 4 pesquisadoras do Distrito Federal. Do México, dois pesquisadores da Universidade

Rev. Iberoam. Patrim. Histórico-Educativo, Campinas (SP), v. 5, p. 1-8, e019001, 2019. 


\section{$(\mathrm{cc})$ EY}

Pedagógica Nacional e 1 pesquisadora e um pesquisador do Departamento de Investigações Educativas-CINVESTAV, Cidade do México.

\section{ARTIGO}

A seção Artigo, como a anterior, agrega ascendência diversa, são pesquisadores e pesquisadoras de Universidades como a Federal do Pará, Universidade Federal da Paraíba, Universidade Federal de Pelotas, Universidade Federal de Pernambuco, Universidade de São Paulo, Universidade Federal de Goiás, Universidade Federal do Espírito Santo, Universidade de Taubaté, do Brasil. Em nível Internacional, Universidad de VIC - Universidad Central de Catalunya, Universidad de León, Universidad Pública de Navarra.

A leitura dos textos publicados na seção evidencia a multiplicidade dos temas advindos dos diferentes estudos. Ao virem a público remetem para a abundância das fontes, em materialidade e imaterialidade contidas, abrindo veredas possíveis à preservação, ao estudo e à difusão do patrimônio histórico educativo e cultural.

Os textos publicados nesta seção trazem em seus títulos a profusão temática já anunciada:

- Em "Uma proposta de fomento à salvaguarda do patrimônio paleontológico da Praia do Atalaia, Pará, Brasil”, é destacada a preocupação com a disponibilização ao público dos fósseis desta região Amazônica;

- O grupo de pesquisadora do MUVIP (Museu Virtual de Pedagogia) da Universidade de VIC, Universidade Central da Catalunha, apresenta "O registro de documentários e notícias, uma oportunidade para acrescentar a documentação do patrimônio histórico educativo" com contribuição inegável ao estudo e à difusão dessas fontes;

- O texto "Museu Simeão Cananeia" - um espaço de história e educação em Bananeiras" da Universidade Federal da Paraíba, busca proximidade à história local com recurso da educação patrimonial;

- "Olhares para educação em terreiros de quimbanda" - Universidade Federal de Pelotas busca olhar os terreiros enquanto pedagogias culturais, a partir das experiências de educação patrimonial; 
$(\mathrm{cc}) \mathbf{E Y}$

- Ensino de história pelos estudantes das escolas Erem Porto Digital e Erem Paulista (Pernambuco/ Brasil), com projeto em escolas estaduais de referência do Ensino Médio com o objetivo de vivenciar a Educação Patrimonial através do estudo da História Local;

- Las escuelas rurales de una comarca leonesa - Facultad de Educación, Universidad de León - buscou a coletar e documentar os edifícios escolares rurais situados na comarca de Maragatería;

- Patrimônio cultural e educação patrimonial: a operação historiográfica e a tática marginal - Universidade de São Paulo, reflete sobre as relações entre o campo do patrimônio cultural e da educação patrimonial, recorrendo à Michel de Certeau;

- A dança popular no contexto da educação física: uma prática crítica e emancipatória nos caminhos do Mestre Griot; coleta de dados a partir de oficinas escolares efetuadas por um Mestre da cultura tradicional da região do Vale do Paraíba Paulista;

- O falso triunfalismo das diretrizes para as culturas populares na américa latina Universidade Federal do Espírito Santo - buscou verificar a valorização e o apoio às culturas populares na América Latina com exame a documentos relativos às temáticas da diversidade cultural e da cultura popular produzidos pela Unesco e a Carta Sul-Americana de Culturas Populares;

- La idea de Francia en la educación de la dictadura franquista (1939-1960) - Departamento de Educación Gobierno de Navarra y Universidad Pública de Navarra - análise dos manuais escolares mais utilizados nos primeiros anos da ditadura franquista, com foco nas publicações da Enciclopedia Álvarez e Editorial Bruño.

\section{RESENHA}

Na seção Resenha, em Educadores e educadoras: gritem contra o racismo, Beatriz Pupin Franco abordou o texto "Negritude, Cinema e Educação: Caminhos para a implementação da Lei 10.639/2003”, de Edileuza Penha Souza; “Estética da Música”, de Enrico Fubini, foi resenhado por André Araújo de Oliveira, em fértil e acalorada apresentação; “(Des)Arquivar: arquivos pessoais e ego-documentos no tempo", de Maria Teresa Santos Cunha, foi apresentado por Gabriela Cordeiro Santos que enfatizou o fato de o estudo (des) arquivar documentos, antes 
$(\mathrm{cc}) \mathrm{BY}$

desconsiderados e hoje revalidados, sobretudo, por fertilizarem pesquisas sobre a memória e as micro-histórias.

\section{DOCUMENTO}

A seção Documento reuniu três propostas que muito engrandeceram a presente edição. “Atas das assembleias da Asphe/RS: documentos para a história da educação", texto com o qual o Prof. Claudemir de Quadros, da Universidade Federal de Santa Maria, RS, brindou a revista ao encaminhar para publicação documento de tamanho significado. Trata-se de documento emblemático que para além de apresentar o percurso histórico da Asphe/RS: Associação Sul-RioGrandense de Pesquisadores em História da Educação, abre para que o leitor possa usufruir de uma verdadeira aula sobre questões ordinárias em nível institucional, que se passam muitas vezes sem a necessária compreensão do significado e elaboração, tais como as Atas; em "Cinquentenário do Centro Paula Souza Documento Histórico no Centro de Memória da Educação Profissional e Tecnológica - Documento em Destaque: Discurso da "Aula inaugural do Centro Estadual de Educação Tecnológica" a Profa. Maria Lucia Mendes de Carvalho, curadora do Centro de Memória da Educação Profissional e Tecnológica, do Centro Paula Souza, apresentou documento da "Aula Inaugural do Centro Estadual de Educação Tecnológica São Paulo", proferida pelo governador Roberto de Abreu Sodré, em 3 de agosto de 1970, no auditório da sede da Federação das Indústrias do Estado de São Paulo; em "Estéticas das resistências e o documentário: diário de exus", o Prof. Gilberto Alexandre Sobrinho, do Instituto de Artes, UNICAMP, apresenta documentário dirigido por ele, o primeiro da "Trilogia Afro-Campineira", série de três curtas-metragens focados em protagonistas de processos culturais, religiosos e artísticos, todos defensores de manifestações de matrizes africanas e seus potentes hibridismos. $\mathrm{O}$ Prof. Gilberto destaca que todo o processo de realização implicou em amplas vivências comunitárias, no desdobramento de relações afetivas potentes que incrementaram o sentido das narrativas.

A apresentação do texto pelo autor permite abrir para uma outra discussão, a dimensão visual do documento escrito, para além das imagens fotográficas, como quando emerge da apresentação visual do texto quadro com inserção de "script e personagens" "Gostoso de ler, 
(cc) EY

gostoso de ver". Outrossim, a marca presente e forte da referência primeira, manifestações culturais de grupos étnico raciais em espaço e tempo precisos.

Ulpiano Bezerra de Meneses já havia chamado a atenção para o fato de as fontes de investigação não precisarem ser obrigatoriamente e muito menos, exclusivamente, fontes materiais, uma vez que podem ser orais, escritas, visuais, materiais, ao que se inclui as fontes ambientais (Meneses, 2013).

A revista, em seu escopo, anuncia a amplitude dos estudos que agasalha e a abertura para a recepção de textos que estudam não somente a escola, mas também outras instituições culturais afins, a partir de suas culturas, materialidades e imaterialidades, buscando apreendê-las historicamente. E ao afirmar o compromisso em contribuir para a elaboração de propostas de preservação e difusão de acervos que possam subsidiar políticas públicas de preservação das fontes, acredita-se que tais proposições se apliquem a todo tipo de fonte, advindas das diversas formas de manifestação cultural.

Com entusiasmo, o retorno a Ulpiano Meneses, para quem:

Não basta, portanto, somente propor uma ampliação das categorias de "manifestações" culturais — como superar os limites de uma 'cultura letrada' ou do território das 'artes'. Não basta pluralisticamente romper as barreiras entre cultura de elite e popular e falar de sua circularidade. Não basta tombar terreiros de candomblé ao lado de um templo católico. Tudo isso é avanço, mas pode transformar-se em reles mecanismo compensatório. É preciso, isto sim, garantir à cultura a possibilidade de transformar a vida inteira - sem eliminar as tensões que isso implica. Para resumir, é preciso combater o conceito de cultura-cólica. essa visão espasmódica da cultura concentrada em formas, espaços e momentos delimitados e que logo entra em relaxamento, tudo voltando ao que era antes. Ao contrário, é a totalidade da experiência social que deve ser o alvo da qualificação cultural. Se há lugar para prioridades, estas devem apontar para o cotidiano e o(s) universo(s) do trabalho. E o patrimônio cultural tem nesse campo uma de suas funções principais. (Meneses, 2008, p. 33)

\section{NOTÍCIA}

Na seção Notícia, a divulgação do VII Simpósio Iberoamericano: História, Educação, Patrimônio-Educativo. VII Simpósio da RIDPHE: Rede Iberoamericana do Patrimônio Histórico-Educativo. Que ocorreu no CEINCE - Centro Internacional de Cultura Escolar, 
Berlanga de Duero/Soria/Espanha, de 22 a 25 de julho de 2019. Informes no

Blog: https://sihepe.blogspot.com/

Para 2020 se anuncia o XIII Encontro Maranhense de História da Educação, em São Luis, MA, de 19 a 22 de maio de 2020, com o tema: Cultura Material Escolar na Gramática da Escola;

- Coloquio Internacional Museologia participativa y Crítica, de 1 a 3 de julho de 2020, sob a organização do Museo de la Educación Gabriela Mistral, em Santiago, Chile.

\section{REFERENCIAS}

MENESES, Ulpiano Bezerra. Da arqueologia clássica ao patrimônio cultural:

Os sentidos da cultura material e seus desdobramentos. In: Cerimônia do Título de Professor Emérito. São Paulo, Gráfica da FFLCH, Universidade de São Paulo, 2008. p. 17-35

MENEZES, Ulpiano Bezerra. Fontes Visuais, cultura visual, história visual. Revista Brasileira de História. São Paulo, v. 23, nº 45, 2003.

VALENTE, Wagner Rodrigues. Apresentação Dossiê Temático: Materiais para o ensino de matemática nos primeiros anos escolares: condensando saberes pedagógicos e disciplinares. Ridphe-r, Revista Iberoamericana do Patrimônio Histórico-Educativo, Campinas (SP), v. 05, p. 1-2, 2019. 